\title{
Desenvolvimento profissional docente: desafios e tensionamentos na educação superior na perspectiva de coordenadores de área
}

Eliane de Lourdes Felden ${ }^{\mathrm{I}, \text { II }}$

http://dx.doi.org/10.24109/2176-6681.rbep.98i250.2858

\section{Resumo}

Este artigo focaliza o desenvolvimento profissional docente mediante inquirição no campo da pedagogia universitária. Resulta de pesquisa que envolveu a docência na educação superior, examinada com apoio em autores contemporâneos, que tradicionalmente investigam esse nível de ensino. Constitui estudo qualitativo utilizando entrevistas semiestruturadas com os coordenadores de área que também assumem a função de professores universitários, com o objetivo de conhecer os desafios e tensionamentos para qualificar a ação docente no ensino superior. Infere que essa qualificação pressupõe investir na formação continuada dos profissionais, na tentativa de superar desafios e tensionamentos vividos. Compreende que o trabalho articulado da universidade e dos professores pode provocar rupturas necessárias no processo de ensinar e aprender, na perspectiva de qualificar a ação docente na universidade.

Palavras-chave: educação superior; docência universitária; desenvolvimento profissional docente. 


\title{
Abstract \\ Teacher professional development: challenges and tensions in higher education through the perspective of the heads of department
}

This research focuses on teacher professional development through an inquiry in the field of university pedagogy. It stems from a research on higher education teaching, substantiated by contemporary authors that traditionally investigate this level of education. This paper constitutes a qualitative study, using semi-structured interviews with heads of department who double as university professors, aiming to learn the challenges and tensions faced in the betterment of higher education teaching. It is inferable that this improvement entails continuing professional-training investment in an effort to overcome experienced challenges and tensions. There is an understanding that the articulated work of the university and its professors can spark needed ruptures in the teaching/learning process, in the perspective of improving teaching in the university.

Keywords: higher education; university teaching; teacher professional development.

\section{Introdução: os desafios e tensionamentos no desenvolvimento profissional docente}

\begin{abstract}
Critica-se e escreve-se muito sobre ensino superior, mas produz-se pouco conhecimento sobre a pedagogia que o sustenta. Por isso, direcionamos as pesquisas para a busca de entendimentos sobre a revitalização da qualidade do ensino universitário e as mudanças que redesenham o perfil das universidades contemporâneas [...]. (Leite, 2003, p. 310).
\end{abstract}

Nos últimos anos, alguns estudos têm sido realizados visando compreender o processo de desenvolvimento profissional do professorado. Além do olhar para a formação docente, essas pesquisas se concentram em conhecer concepções, comportamentos, crenças, desafios e tensionamentos vividos pelos educadores. Na verdade, há uma preocupação com o desenvolvimento profissional dos professores, reconhecidos como importantes atores do sistema educacional.

Com base nas diversas abordagens sobre o desenvolvimento profissional docente, apresenta-se como objetivo geral deste estudo conhecer e compreender os desafios e tensionamentos para qualificar a ação docente na universidade, na perspectiva dos professores da educação superior, que também desempenham a função de coordenadores de área. O coordenador de área é o profissional que assume a atribuição de acompanhar e assessorar os diversos aspectos acadêmicos de cursos que integram determinado campo do conhecimento. Um exemplo é a coordenação de ciências humanas, que acompanha e assessora o trabalho dos coordenadores dos cursos de pedagogia, matemática e psicologia. 
Segundo Marques (2001), é fundamental para a investigação que uma dúvida seja muito bem definida. Logo, como problema de pesquisa, destacou-se a indagação: quais os desafios e tensionamentos para qualificar a ação docente na universidade, na perspectiva dos coordenadores de área?

Nesse contexto, este estudo defende que a formação continuada dos professores constitui compromisso das instâncias administrativas das universidades, mas ela precisa ser planejada com base nas necessidades dos professores e respectivos departamentos. O que se observa é que aprender a ensinar vincula-se, em definitivo, à construção do conhecimento profissional docente. Ou seja, é fundamental que o professor se qualifique para ser docente, uma vez que existem saberes específicos para esse ofício. Embora o professor viva processos de autoformação e possa realizá-los individualmente, acredita-se que a reflexão compartilhada e conjunta precisa acontecer.

A universidade é, portanto, não apenas um espaço de ação, mas também de formação do professor da educação superior. Neste estudo, buscou-se aprimorar a reflexão acerca da pedagogia universitária, iluminando-a em vez de refrear a complexidade das questões que nela se incluem. Fazer uma abordagem sintética da tese exigiu estruturar o presente artigo nas etapas apresentadas a seguir.

\section{$O$ contexto da pesquisa}

O trabalho ${ }^{1}$ investigativo proposto se apoiou em uma pesquisa qualitativa, realizada no período de outubro de 2012 a janeiro de 2013, com foco na epistemologia da prática profissional dos professores e no processo de desenvolvimento em direção a uma docência de melhor qualidade. Essa pesquisa explicita e aprofunda alguns conceitos que se articulam ao trabalho do docente universitário.

Nos estudos realizados, foi possível compreender a pesquisa como atividade fundamental das ciências na investigação e descoberta da realidade. O contexto se deu em uma universidade comunitária do interior do estado do Rio Grande do Sul, com participação e envolvimento dos coordenadores de todas as grandes áreas ${ }^{2}$ do conhecimento.

Em uma pesquisa de abordagem qualitativa, Minayo (2000) orienta que o critério da amostra não seja numérico, e sim revele a totalidade nas suas dimensões. Buscando compreender a realidade universitária, foram utilizadas como instrumentos para realizar a pesquisa entrevistas individuais semiestruturadas, por serem consideradas estratégia fundamental nas investigações de campo, apoiadas em roteiro com perguntas fechadas e abertas, que levam a "flexibilidade nas conversas e a absorver novos temas e questões trazidas pelo interlocutor" (Minayo, 2010, p. 191).

As entrevistas foram aplicadas a sete coordenadores de área da referida instituição, gravadas com a autorização prévia ${ }^{3}$ e, posteriormente, transcritas. $\mathrm{O}$ acesso aos entrevistados foi realizado mediante a autorização 
solicitada à direção acadêmica da universidade. A investigação com os próprios pares foi motivada pelo compromisso social com a instituição, especialmente com a qualificação do processo de formação profissional na universidade, reconhecendo os coordenadores envolvidos como protagonistas nesse processo.

Dos sete entrevistados, seis possuíam mais de dez anos de atuação na educação superior e respondiam pela gestão das seguintes áreas: ciências humanas; linguística, letras e artes; ciências da saúde; ciências sociais aplicadas; ciências biológicas; ciências exatas e da Terra; engenharias e ciência da computação.

Para análise dos dados, optou-se por observar o conteúdo dos discursos dos sujeitos, com base nas contribuições de Bakhtin (2004), Bardin (1979) e Minayo (2010). A palavra é um prodígio, por excelência, que permitiu apreender as particularidades dos participantes da pesquisa. A análise de conteúdo favoreceu o estudo do teor das mensagens emitidas por eles, o que contribuiu para a definição de categorias, como desafios da função do coordenador de área, formação para docência, desenvolvimento profissional e formação, incluindo ações institucionais.

\section{A docência na educação superior: problematização}

Como ser professor neste mundo? Como fazer o exercício da docência? Que recursos usar para atender às demandas que se colocam? Como os saberes da docência podem auxiliar o professor na direção de uma atuação competente? (Rios, 2008, p. 56).

O desafio de estudar e analisar a docência na educação superior continua presente no campo da pedagogia universitária como tema iminente, tendo em vista as pressões e demandas colocadas à universidade na contemporaneidade. É um assunto complexo, que tem sido pensado e discutido em pesquisas e eventos afins, mas há um reconhecimento que ainda é pouco debatido no interior das instituições universitárias.

Ao analisar a trajetória da universidade, ao longo da história da educação, compreende-se que a docência assumiu contornos de acordo com as condições políticas, sociais, econômicas e culturais de cada época. As políticas públicas implementadas e as constantes demandas da sociedade exerceram e continuam impactando na docência, pois, à medida que a sociedade muda, a universidade também constrói novas formas de atuação conforme as circunstâncias locais, regionais, nacionais e internacionais.

Behrens (2005) declara que, historicamente, a ação docente foi assinalada por uma abordagem positivista. Nessa dimensão, afirma que é imprescindível buscar caminhos alternativos para o professor ultrapassar essa lógica, examinando os paradigmas da ciência e a influência desses nas abordagens pedagógicas.

Para essa autora, a especialização anunciada pela percepção cartesiana foi discutida mais intensamente nas décadas de 1980 e 1990, tendo em vista a seguinte premissa: 
[...] o tecnicismo, com um posicionamento positivista, levou ao desenvolvimento científico-tecnológico do mundo atual. Portanto, a abordagem técnica tem sua relevância, pois o sucesso do desenvolvimento da ciência moderna foi assentado no surgimento de novas técnicas eficazes. No entanto, a abordagem técnica tem contemplado enfaticamente os aspectos externos das experiências (lucro, domínio, poder), ignorando o indivíduo. O homem no século XX alienou-se da natureza, do trabalho criativo, de si mesmo e dos outros. (Behrens, 2005, p. 22).

Segundo a autora, esse tecnicismo que produziu acentuado desenvolvimento científico-tecnológico não se caracteriza como erro histórico, mas processo importante para o pensamento humano, apesar de ter provocado um vazio incitado pela competitividade, em que a cobrança de eficiência e eficácia em defesa de um produto e de um capital está presente. Argumenta ainda que a promessa de felicidade plena do homem pela aplicação das tecnologias também não se concretizou. Exemplos disso são a miséria e a fome que, em pleno século 21, assolam países em desenvolvimento, além da miséria psicológica marcada pela solidão, indiferença e violência que caminham lado a lado com o conforto dos países desenvolvidos.

De acordo com Behrens (2005), essa crise mundial atinge, de forma significativa, o contexto educacional, considerando que o pensamento newtoniano-cartesiano carrega marcas que afetam os sujeitos que integram as instituições em todos os níveis de ensino. E, assim, assevera:

\begin{abstract}
A visão fragmentada levou os professores e os alunos a processos que se restringem à reprodução do conhecimento. As metodologias utilizadas pelos docentes têm estado assentadas na reprodução, na cópia e na imitação. A ênfase do processo pedagógico recai no produto, no resultado, na memorização do conteúdo, restringindo-se em cumprir tarefas repetitivas que, muitas vezes, não apresentam sentido ou significado para quem as realiza. (Behrens, 2005, p. 23).
\end{abstract}

Do ponto de vista da autora, em especial no início do século 20, professores e alunos aceitavam as questões da instituição como verdades absolutas e inquestionáveis, limitando-se a reproduzir os conhecimentos historicamente construídos. As metodologias desenvolvidas pelos professores não oportunizavam o questionamento e a expressão do pensamento e, assim, com passividade e autoritarismo, dava-se o processo de ensino e aprendizagem.

Nesse sentido, há necessidade de superar o pensamento newtonianocartesiano, não no sentido de anular, mas de avançar qualitativamente considerando as novas exigências. Há uma compreensão de que, no âmago do paradigma anterior, é que um novo paradigma é construído.

\title{
O professor e o processo de transição paradigmática
}

Na sequência do processo de reflexão sobre o trabalho dos professores e as interfaces das mudanças paradigmáticas necessárias e discutidas na contemporaneidade, é possível compreender os vários determinantes que 
interferem na prática docente, em especial a visão de ciência, de homem, a forma como se concebe e se direciona o conhecimento, além do reconhecimento da função da universidade.

Santos (1999), ao explicitar a indispensável ruptura da visão moderna em direção à pós-moderna, esclarece que o modelo de racionalidade que preside a ciência moderna surgiu a partir da revolução científica verificada no século 16 e se desenvolveu nos séculos seguintes, declarando como válidas apenas duas formas de conhecimento: disciplinas formais da lógica e da matemática e ciências empíricas. Conhecer, na visão moderna, requer a quantificação e o rigor das medições como fundamento da cientificidade; impõe a divisão e classificação para depois instituir relações com o que foi separado, assegurando a apreensão da parte. Com base no quantificado, compreendem-se a ordem, as leis e os princípios que afirmam a estabilidade e as relações causais entre os fenômenos.

Na visão moderna de ciência, alguns princípios estão presentes: a rigidez do método, que se torna tão ou ainda mais importante que o objeto de estudo; o desconhecimento do homem como sujeito empírico e sua identificação como sujeito epistêmico; um conhecimento factual que não admite interferência de valores, dividindo sujeito e objeto; a ênfase na especialização, porém, sem desenvolver processos integrativos; e o senso comum concebido como superficial, fictício e enganoso, buscando, em sua ruptura epistemológica, o salto qualitativo para o conhecimento científico (Cunha, 2005).

Já a visão pós-moderna, apresentada por Santos (1999), provoca pensar na necessária transgressão metodológica, perceber que a inovação científica pressupõe inventar contextos persuasivos que levam à aplicação dos métodos fora de seu contexto natural e compreender os propósitos metafísicos, os sistemas de crenças e valores como elementos integrantes da explicação científica e o objeto, como prolongamento do sujeito. O autor reitera que todo conhecimento faculta o autoconhecimento, sendo autobiográfico.

Na obra de Cunha (2005), encontram-se igualmente estudos em torno do salto qualitativo da visão moderna da ciência para a pós-moderna. Ao argumentar a respeito dos pressupostos que precisam calcar um trabalho pedagógico com base em uma perspectiva pós-moderna de ciência, a pesquisadora evidencia que é essencial enfocar o conhecimento, sempre considerando a localização histórica de sua produção, reconhecendo-o como provisório e relativo. Também defende a ideia de que é imprescindível percebê-lo de forma interdisciplinar, estabelecendo pontes entre os conhecimentos e conferindo significados próprios aos conteúdos, em função dos objetivos sociais e acadêmicos.

\section{Professor universitário: compromissos e responsabilidades}

Analisar o exercício da função de professor universitário aponta para a necessidade de reconhecer e compreender compromissos e 
responsabilidades da docência no intuito de fortalecer os processos de ensinar e aprender na universidade.

Em relação à universidade como instituição social, Zabalza Beraza (2004, p. 35) argumenta que é esperada a realização de inúmeras funções e destaca, entre elas:

[...] ensino, pesquisa, administração dos recursos e do pessoal, dinamização social e cultural, apoio técnico e científico às empresas, consultoria social, serviço social e apoio às pessoas de baixa renda, estabelecimento de parcerias nacionais e internacionais de pesquisa e formação, crítica social, etc.

Dessa maneira, observa-se que a universidade é chamada a assumir-se como espaço privilegiado para fortalecer os valores culturais e sociais, além da própria preservação e difusão crítica do conhecimento. Também está presente, nesse debate, o trabalho da universidade com a pesquisa, objetivando aumentar e propagar uma base de conhecimentos na sociedade, organizando-se como força impulsionadora do desenvolvimento, por meio de parcerias.

Diante dessas considerações, Zabalza Beraza (2004) afirma que a principal ocupação da universidade é com a formação do sujeito, pois, em relação à docência, formação é tarefa fundamental do professor universitário. Para responder a tantas demandas, o professor vive tensionamentos legítimos. A proposta do estudo é viabilizar a compreensão desses tensionamentos para revitalizar a qualidade na educação superior.

\section{Compreender tensionamentos para revitalizar a qualidade: palavra dos docentes universitários - coordenadores de área}

Há um desassossego no ar. (Santos, 2000, p. 41).

Construir novo paradigma, fazer rupturas no interior, nas entranhas das continuidades e buscar sustentação em outras epistemologias parece ser um tensionamento emergente colocado aos professores universitários nos dias atuais.

Na obra de Santos (1995, tradução nossa), a construção de novo paradigma conjectura nova epistemologia, que não aceita a falta de esperança e possibilidades, apresentando alternativas e, ainda, nova psicologia que não considera o aspecto subjetivo da conformidade, e sim fomenta o desejo de lutar por tais vicissitudes.

A ideia é de que se vive um período de transição paradigmática que exige alterações, convertendo a concepção de "[...] conhecimento-comoregulação em conhecimento-como-emancipação" (Santos, 1995, p. 481). Essa conversão pode se dar de forma gradativa, em que as dinâmicas dominantes são substituídas pelas forças emergentes e pela própria contradição e rivalidade entre paradigmas. 
Essencialmente, o conhecimento como emancipação precisa ser perseguido, isto é, as mudanças requeridas apontam que os fundamentos éticos, científicos, ideológicos ou paradigmáticos, em uma dimensão epistemológica e social, são tarefa possível de ser concretizada.

Conhecer as concepções atuais dos professores universitários pressupõe refletir acerca das circunstâncias presentes para se estabelecer possibilidades para o futuro. Ao entrevistar docentes que hoje atuam no contexto do ensino superior como coordenadores de área, foi possível identificar unidades de significado, no intuito de compreender seus desafios e tensionamentos para qualificar a docência. Neste artigo, explicitam-se algumas delas, que são desafios da função do coordenador de área: pressões para o exercício da docência qualificada; formação para a docência; desenvolvimento profissional e formação - ações institucionais.

\section{Desafios da função do coordenador de área: pressões para o exercício da docência qualificada}

Ao escutar os interlocutores da pesquisa, em geral, percebe-se que há, por parte deles, uma preocupação em conhecer o funcionamento de cada curso e respectivos procedimentos internos, a fim de acompanhar os coordenadores, orientando o planejamento e, sobretudo, respondendo aos índices e instrumentos de avaliação propostos pelo Ministério de Educação (MEC). Segundo uma coordenadora da área de linguística, letras e arte, "[...] o maior desafio é organizar o projeto pedagógico do curso de forma a atender às demandas sociais, da legislação e das diretrizes da área e, especialmente, com vistas à avaliação do curso pelo MEC".

Em suas narrativas, os coordenadores revelam a preocupação com a elaboração e definição das prioridades no projeto pedagógico do curso (PPC) e, ainda, com a legislação vigente, uma vez que esta regula o funcionamento dos cursos na educação superior e sua falta de cumprimento pode acarretar sérios prejuízos ao curso e à própria instituição.

A avaliação do curso, realizada pelo MEC, também preocupa os coordenadores, o que evidencia a preponderância do Estado avaliador, contribuindo para que os resultados produzidos no interior das instituições sejam, de forma permanente, sujeitos a um julgamento público.

Os movimentos empreendidos para favorecer a qualidade da educação superior também foram foco de estudo e análise junto aos sujeitos. De acordo com coordenadores de área, observa-se que os procedimentos para qualificar a docência e o próprio andamento do curso foram múltiplos e podem ser assim sintetizados pela fala de uma coordenadora da área de ciências sociais aplicadas: "incentivo aos docentes para que utilizem mais os materiais disponíveis na biblioteca e, dessa forma, incentivem os discentes para aumentarem o número de grupos de pesquisa e extensão dentro de cada curso".

É importante referir esse chamamento aos professores para que constituam pesquisadores, objetivando qualificar, cada vez mais, a 
educação superior, e para que sejam capazes de sensibilizar os alunos comprometendo-se com a estratégia inovadora de ensinar com pesquisa.

Segundo Anastasiou e Alves (2010), o ensino com pesquisa é uma das estratégias defendidas como trabalho relevante a ser desenvolvido pelos professores universitários. Em seus estudos, essas autoras argumentam que

o ensino com pesquisa oferece condições para que os estudantes adquiram maior autonomia, assumam responsabilidades, desenvolvam disciplina, tomada como habilidade de se manter o tempo necessário na busca da solução de problemas até o esgotamento das informações, com treino de trabalho intelectual a ser supervisionado pelo professor. (Anastasiou; Alves, 2010, p. 105).

Nas considerações das autoras, ensino com pesquisa remete ao desenvolvimento de pensamento objetivo, crítico, construtivo e autônomo. Argumentam que o processo de construção do conhecimento abarca mobilização e elaboração da síntese do saber, provocando o acadêmico a se ver como construtor da realidade, ampliando sua visão sobre ela.

Uma coordenadora da área de saúde, ao ser interrogada sobre seu compromisso para qualificar a educação superior, afirma que ele perpassa o planejamento do ensino e complementa:

[...] esse planejamento deve atender às diretrizes curriculares de cada curso, além dạs exigências impostas pelo MEC na avaliação dos cursos superiores. E importante haver um comprometimento de todo o colegiado de cada curso com a qualidade e o conhecimento do projeto pedagógico do curso e o envolvimento do corpo discente com o curso.

Há uma preocupação em explicar que, para atender a essas questões, é necessário que o corpo docente proporcione aos acadêmicos, além dos conhecimentos do ensino em sala de aula, atividades relacionadas à pesquisa e à extensão.

Dessa forma, os coordenadores precisam estar muito afinados com seus professores para juntos atribuir qualidade ao processo formativo. Esse movimento perpassa o estudo das diretrizes curriculares para cada curso, a construção e o conhecimento do PPC, além da definição de ações que fortaleçam o ensino, a pesquisa e a extensão. É um olhar que examina a atividade docente de forma abrangente, em que os professores e o gestor da área necessitam construir conhecimentos para além do campo específico, bem como habilidades e responsabilidades compartilhadas. Recorda-se de importante pressuposto que legitima essa narrativa: "[...] se espera o envolvimento desses professores na administração e gestão em seus departamentos, na universidade, tomando decisões sobre currículo, políticas de pesquisa e financiamento [...]" (Pimenta; Anastasiou, 2008, p. 39).

A ampliação dos grupos de pesquisa e a extensão também são defendidas pela coordenadora entrevistada como caminho para qualificar o processo educativo na universidade. Compreende-se que os grupos de pesquisa e a extensão proporcionam uma cooperação acadêmica no processo de formação, que, pautada no diálogo e nas parcerias, intensifica 
o intercâmbio científico, criando condições para a elevação da qualidade da educação superior.

É imprescindível, nesse movimento, compreender a necessária profissionalidade docente, reconhecida como a afirmação do que é específico na ação do professor ou "o conjunto de comportamentos, conhecimentos, destrezas, atitudes e valores que constituem a especificidade de ser professor" (Gimeno Sacristán, 1995, p. 65).

\section{Formação para a docência}

Outra unidade de significado examinada nos depoimentos é em relação à formação esperada para o professor atuar na educação superior. Nessa perspectiva, assim afirma um dos entrevistados:

[...] o professor, principalmente aquele que não tem formação na área da licenciatura, deve buscar os conhecimentos de modo a suprir esta carência na sua formação. Nesse ponto, a formação continuada tem um papel muito importante [...], pois precisa suprir esta carência [...] e funcionar como atualização para os professores com formação pedagógica. (Coordenadora da área de ciências da saúde).

Esse mesmo pressuposto é defendido por outra coordenadora ao afirmar que,

[...] além da formação acadêmica necessária, todo professor precisa ter formação pedagógica, pois essa é que garante resultados positivos das aulas. Conhecimento da área específica de formação e conhecimento pedagógico são eixos necessários para a atuação docente, além dos conhecimentos do eixo de formação geral. (Coordenadora da área de linguística, letras e arte).

Fica evidente, na concepção dos coordenadores, que os conhecimentos pedagógicos são afirmados como necessários, assim como os conhecimentos específicos da área e de formação geral. De fato, isso configura a docência universitária como atividade complexa, pois envolve uma multiplicidade de saberes e competências, o que representa um trabalho interativo cuja perspectiva é o domínio de um conjunto de conteúdos que orientam a formação docente. Chama atenção, no entanto, que há uma delegação da procura dessa formação para o indivíduo. Igualmente, há um reconhecimento de que a formação docente precisa ser continuada, pois a experiência profissional é importante, mas não assegura a qualidade.

A formação contínua ocupa lugar importante na narrativa das coordenadoras, manifestada como um processo posterior à formação inicial, visando ao aperfeiçoamento profissional, especialmente os saberes, as estratégias metodológicas necessárias ao exercício da profissão. No entanto, aconselha-se que esse movimento pela qualificação profissional tenha alvos individuais, uma vez que "a formação contínua tem como finalidade última o aperfeiçoamento pessoal e social de cada professor, numa perspectiva de educação permanente" (Formosinho, 1991, p. 238). 
Porém, não se trata de responsabilizar unicamente o professor pelo seu desenvolvimento profissional docente, enquanto a instituição se livra desse compromisso. Nessa direção, Correia e Matos (2001) asseveram a relevância da formação continuada, desde que seja desenvolvida de forma coletiva, compartilhada, e não individualizada.

\section{Desenvolvimento profissional e formação: ações institucionais}

O desenvolvimento profissional docente foi mais uma unidade de significado que emergiu das narrativas dos interlocutores da pesquisa. $\mathrm{Na}$ perspectiva de uma das coordenadoras, para promover o desenvolvimento profissional docente, é necessário

[...] que este possa transitar, de forma efetiva, tanto no ensino em sala de aula quanto na pesquisa e na extensão, uma vez que a pesquisa abre novos caminhos, descobertas e aprimoramento do conhecimento, e a extensão cumpre o papel de poder testar as teorias estudadas e, a partir dessa vivência, criar novas teorias, além de propiciar uma ligação entre o ensino superior e a comunidade local. (Coordenadora da área de ciências sociais aplicadas).

Outra coordenadora acredita que o desenvolvimento profissional se dá quando o professor disponibiliza de

tempo para estudar e atualizar-se não só pensando nos cursos de mestrado e doutorado, mas nas pequenas coisas, como cursos de atualização, pesquisa de periódicos da sua área e a realização de projetos de pesquisa e de extensão. (Coordenadora da área de ciências da saúde).

Nesse sentido, vale reafirmar que "a docência universitária exige a indissociabilidade entre ensino, pesquisa e extensão. Faz parte dessa característica integradora a produção do conhecimento bem como sua socialização" (Veiga, 2006, p. 87).

Examinar esse pressuposto significa entender que o processo de desenvolvimento da docência universitária implica trabalhar contemplando a indissociabilidade entre ensino, pesquisa e extensão, compreendendo que esse movimento atribui maturidade profissional aos professores.

Curiosamente, dos sete coordenadores de área entrevistados, apenas uma afirmou que a instituição tem realizado formação continuada para professores. O incentivo à participação em eventos afins, fora da instituição, apareceu na narrativa de três dos sete coordenadores de área. Todos eles reconhecem que esse apoio estimula o desenvolvimento profissional, pois oportuniza a participação em eventos que proporcionam a revisão sistemática do próprio exercício da docência.

Destaca-se, nesta unidade de significado, a seguinte narrativa:

Em outros anos, aqui no campus, tivemos alguma experiência com formação de professores. A adesão foi baixa, o investimento mínimo. Hoje, não temos nada institucionalizado na esfera da unidade - campus. (Coordenadora da área de ciências humanas). 
Fica evidente que os professores reconhecem que não é oferecida formação continuada a eles, não há projeto institucionalizado de formação para docentes, os quais manifestam, claramente, que é preciso oferecer projeto de qualificação permanente que contemple questões específicas de cada área, questões pedagógicas, entre outras.

Essa denúncia dos profissionais, quanto à falta de projeto de formação continuada para os professores que atuam na educação superior, preocupa, mas, ao mesmo tempo, revela certa expectativa, pois os coordenadores reconhecem ser uma política necessária, que deve ser assumida pela universidade ao definir possibilidades para qualificar o exercício da docência.

\section{Considerações finais}

Somente estudando, analisando e debatendo a realidade da universidade, estaremos em condições de ter ideias mais claras em relação ao modo como podemos melhorar a qualidade do trabalho universitário. (Zabalza Beraza, 2004, p. 8).

O compromisso social com a melhoria da educação superior mobilizou este estudo em torno da pedagogia universitária, que tem o ensinar, o aprender e o avaliar, na universidade, como objetos de estudo. Fundamentalmente, a abordagem desta pesquisa recaiu na constituição da profissionalidade docente, seus desafios e tensionamentos no contexto social e político da sociedade brasileira contemporânea.

Considerando as diversas abordagens sobre o desenvolvimento profissional docente, tem-se como objetivo geral conhecer e compreender os desafios e tensionamentos para qualificar a ação docente na educação superior, na perspectiva dos coordenadores.

Elucidar a temática exigiu lançar mão de literatura nacional e internacional na busca de estudos que apoiam o aprofundamento do tema, bem como estabelecer articulação com os saberes construídos pelos profissionais que atuam na educação superior, exercitando, assim, um movimento de apreensão, em uma tentativa de se buscar respostas para qualificar a prática docente na universidade.

Responder ao problema de pesquisa demandou examinar os desafios e tensionamentos para qualificar a ação dos coordenadores e professores na universidade. Os coordenadores de área manifestam como principal desafio e tensionamento conhecer o funcionamento de cada curso e seus procedimentos internos para acompanhar os coordenadores e professores, orientando o planejamento em geral, mas, em especial, respondendo aos índices e instrumentos de avaliação propostos pelo Ministério de Educação. Em suas narrativas, os coordenadores revelam preocupação com a elaboração e definição das prioridades no projeto pedagógico do curso e, ainda, com a legislação vigente, uma vez que esta regula o funcionamento dos cursos no ensino superior e o seu não cumprimento pode acarretar sérios prejuízos ao curso e à própria instituição. 
Outro desafio apontado foi a administração do tempo para o cumprimento das demandas oriundas de diferentes cursos. A infraestrutura, a qualificação do corpo docente e as exigências de publicações, tendo em vista as avaliações externas, também aparecem na narrativa dos coordenadores de área.

As questões que direcionaram a pesquisa remetem a responder que, conforme os professores da educação superior, a formação necessária para atuar como docente na universidade é a graduação e a pós-graduação na área em que vai lecionar, ou seja, uma formação acadêmica e uma pedagógica. Para tanto, uma política de desenvolvimento profissional para os professores, com o objetivo de aprimorar a dimensão didático-pedagógica e específica, que acompanhe e sustente o trabalho deles parece ser bem aceita pelos coordenadores.

Quanto às necessidades de formação, foi possível verificar que, segundo os coordenadores, é imprescindível construir caminhos em direção ao desenvolvimento profissional dos professores por parte da instituição, reconhecendo o papel do docente no desenvolvimento social. Esse tensionamento que ronda o trabalho da educação superior precisa ser assumido por gestores e demais profissionais que atuam na universidade. Seriam encontros periódicos que oportunizassem discutir a formação em um movimento que articulasse análise e reflexão da prática profissional, seus desafios e tensionamentos, pois isso compõe valor e elemento fundamental para a profissionalidade.

A modalidade de formação que mais agrada e que acreditam ser mais efetiva para a qualificação de seu trabalho, de acordo com os coordenadores, são programas que estimulem o professor a buscar melhorar sua formação, principalmente em cursos de longa duração, como mestrados e doutorados, dando aos docentes condições para que possam dar continuidade à formação. A criação de espaços de socialização de experiências entre as diversas áreas do conhecimento também foi revelada como essencial. Igualmente, foi explicado que os investimentos na formação dos profissionais necessitam considerar a área de formação e de atuação deles. Alguns afirmam que os programas de formação continuada precisam ser convocados, de atendimento obrigatório, em diferentes níveis, como palestras bimensais e encontros mensais por área e por curso, em que os temas trabalhados pudessem ser refletidos na realidade de cada curso e ali instrumentalizados em novas experiências, resultando em outras posturas e metodologias.

O trabalho de formação, realizado ou não pela instituição onde se está inserido, também foi foco de análise. Poucos assumiram a dimensão da autoformação, mas a maioria dos coordenadores entrevistados afirmou que qualitativa e quantitativamente é imprescindível que a universidade assuma, com rigor, a formação continuada de seus professores. Em especial, os depoimentos mais críticos evidenciam que a formação continuada geralmente é estabelecida pelos departamentos de ciências humanas e educação. Porém, os coordenadores acreditam que a formação dos professores tem que ser compromisso de todos os pesquisadores dentro da 
instituição. Exemplificam que a formação para gestão ou em tecnologia para o ensino precisa estar presente, tanto quanto a pedagógica. A insuficiência pedagógica acerca dos saberes docentes, por parte dos profissionais que atuam na universidade, é admitida pelos coordenadores, mas legitimam que é necessário avançar e, assim, planejar ações que revelem novos valores. Desse modo, no processo de profissionalização como ação coletiva, várias temáticas precisam ser abordadas, examinadas e construídas com os professores. Portanto, um olhar rigoroso ao que é específico da profissionalidade docente precisa permear a formação. Nesse conjunto de circunstâncias, "[...] temos de estar dispostos a modificar as rotinas de nossas ações pedagógicas, de nossos procedimentos didáticos; dispostos a questionar nossos próprios saberes." (Veiga et al, 2008, p. 269).

Ao longo das reflexões, ficou evidente que qualificar a ação do professor na universidade pressupõe investir na formação continuada, como condição fundamental em direção ao desenvolvimento profissional docente, na tentativa de superar os desafios e tensionamentos vividos. Esse pressuposto aparece de forma transversal na perspectiva dos teóricos pesquisados e na narrativa dos próprios coordenadores de área. Para tanto, enfrentar esses desafios expostos pelos coordenadores exige busca constante pela formação que possibilite o debate e o estudo dessas questões, com a finalidade de avançar e qualificar a educação superior.

O campo do ensino pressupõe a procura pelo saber, entretanto, ela não se dá somente de forma solitária, mas coletiva, implicando compromissos individuais e institucionais. Nesse contexto, a tese apresentada neste estudo se consolidou reforçando a compreensão de que o compromisso da formação continuada dos professores está nas instâncias administrativas das universidades, mas ela precisa ser planejada com base nas necessidades dos professores e de seus respectivos departamentos. O que se observa é que aprender a ensinar se vincula, em definitivo, à construção do conhecimento profissional docente

\section{Referências bibliográficas}

ANASTASIOU, L. G. C.; ALVES, L. P. (Org.). Processos de ensinagem na universidade: pressupostos para as estratégias de trabalho em aula. 9. ed. Joinville: Ed. da UNIVILLE, 2010.

BAKHTIN, M. Marxismo e filosofia da linguagem. São Paulo: Hucitec, 2004.

BARDIN, L. Análise do conteúdo. Lisboa: Edições 70, 1979.

BEHRENS. M. A. O paradigma emergente e a prática pedagógica.

Petrópolis: Vozes, 2005. 
BOGDAN, R.; BIKLEN, S. K. Qualitative research for education. Boston: Allyn and Bacon, 1982.

BRASIL. Conselho Nacional da Saúde (CNS). Resolução nº 196 de 10 de outubro de 1996. Estabelece as Diretrizes e Normas Regulamentadoras de Pesquisas envolvendo Seres Humanos. Diário Oficial da União, Brasília, 16 out. 1996. Seção 1, p. 2182.

CORREIA, J. A.; MATOS, M. Solidões e solidariedade na profissão docente: sofrimento e crise da profissionalização dos professores. Porto: ASA, 2001.

CUNHA, M. I. O professor universitário na transição de paradigmas. 2. ed. Araraquara: Junqueira \& Marin, 2005.

CUNHA, M. I. A formação de professores como problema: natureza, temporalidade e cultura. Cadernos de Educação, Pelotas, v. 15, n. 27, p. 55-71, jul./dez. 2006.

CUNHA, M. I. A indissociabilidade do ensino com a pesquisa e a extensão como referente da qualidade na universidade brasileira: um discurso em tensão. In: CUNHA, M. I. (Org.). Qualidade da graduação: a relação entre ensino, pesquisa e extensão e o desenvolvimento profissional docente. Araraquara: Junqueira\&Marin, 2012. p. 17-38.

FORMOSINHO, J. Formação contínua de professores: realidades e perspectivas. Aveiro: Universidade de Aveiro, 1991.

GIMENO SACRISTÁN, J. Consciência e acção sobre a prática como libertação profissional dos professores. In: NÓVOA, A. (Org.). Profissão professor. 2. ed. Porto: Porto Editora, 1995. p. 63-92. (Coleção Ciências da Educação).

IMBERNÓN MUÑOZ, F. La formación pedagógica del docente universitario. Educação: Revista do Centro de Educação, Santa Maria, v. 36, n. 3, p. 387-396, set./dez. 2011.

LEITE, D. B. C. Educação superior. In: MOROSINI, M. (Org.). Enciclopédia de pedagogia universitária. Porto Alegre: FAPERGS/RIES, 2003. v. 1.

LEMOS, A. Cibercultura, tecnologia e vida social na cultura contemporânea. 3. ed. Porto Alegre: Sulina, 2007.

MARQUES, M. O. Escrever é preciso: o princípio da pesquisa. 4. ed. Ijuí: Unijuí, 2001. 
MINAYO, M. C. S. O desafio do conhecimento: pesquisa qualitativa em saúde. 6. ed. São Paulo: Hucitec, 2000.

MINAYO, M. C. S. O desafio do conhecimento: pesquisa qualitativa em saúde. 12. ed. São Paulo: Hucitec, 2010.

NÓVOA, A. (Coord.). Os professores e a sua formação. Lisboa: Dom Quixote, 1995.

NÓVOA, A. (Org.). Profissão professor. Porto: Porto Editora, 1999.

NÓVOA, A. Os professores e as histórias da sua vida. In: NÓVOA, A. (Org.). Vidas de professores. Porto: Porto Editora, 1994. p. 11-30.

PIMENTA, S. G.; ANASTASIOU, L. G. C. Docência no ensino superior. 3. ed. São Paulo: Cortez, 2008.

RAYS, O. A. Ensino-pesquisa-extensão: notas para pensar a indissociabilidade. Caderno Educação Especial UFSM, Santa Maria, n. 21, p. 1-10, 2003.

RIOS, T. A. Compreender e ensinar: por uma docência da melhor qualidade. 6. ed. São Paulo: Cortez, 2006.

RIOS, T. A. A dimensão ética da aula ou o que nós fazemos com eles. In: VEIGA, I. P. (Org.). Aula: gênese, dimensões, princípios e práticas. Campinas: Papirus, 2008.

SEVERINO, A. J. Pressupostos filosóficos da formação e da prática do educador. Cadernos de Educação, Pelotas, v. 15, n. 27, p. 37-54, jul./dez. 2006.

SANTOS, B. Toward a new common sense. New York: Routledge, 1995.

SANTOS, B. Um discurso sobre as ciências. 7. ed. Porto: Edições Afrontamento, 1999.

SANTOS, B. Para um novo senso comum: a ciência, o direito e a política na transição paradigmática. São Paulo: Cortez, 2000. (A crítica da razão indolente: contra o desperdício da experiência, v. 1).

VEIGA, I. P. A. (Org.). Projeto político-pedagógico da escola: uma construção possível. 22. ed. Campinas: Papirus, 2006.

VEIGA, I. P. A. et al. (Org.). Aula: gênese, dimensões, princípios e práticas. Campinas: Papirus, 2008. 
VEIGA, I. P. A. A docência na educação superior e as didáticas especiais: campos em construção. Educação: Revista do Centro de Educação, Santa Maria, v. 36, n. 3, p. 455-464, set./dez. 2011.

ZABALZA BERAZA, M. Formación del profesorado universitario: mejorar a los docentes para mejorar la docencia. Educação: Revista do Centro de Educação, Santa Maria, v. 36, n. 3, p. 397-424, set./dez. 2011.

ZABALZA BERAZA, M. O ensino universitário: seu cenário e seus protagonistas. Tradução Ernani Rosa. Porto Alegre: Artmed, 2004.

Recebido em 26 de julho de 2016.

Solicitação de correções em 10 de julho de 2017.

Aprovado em 11 de agosto de 2017. 